\title{
Integrated system for monitoring road safety performance in cities
}

\author{
G. Al-Haji \\ Linköping University, Dept of Science and Technology, Sweden
}

\begin{abstract}
A strong monitoring system of road safety in a city is necessary to ensure that the strategies implemented will meet stated targets at city and national levels. Although road safety performance is a result of many key indicators, only a few of these indicators are generally considered in monitoring the performance of road safety in a city and in comparison to other cities. A number of monitoring systems are already being developed and used in road safety and they range from relatively simple models to highly complex ones depending on the number of indicators involved, details of data and complexity of methods used in calculations and analysis. In road safety, there are three main types of monitoring that are generally used, which are: Process Monitoring, Outcome Monitoring and Target Monitoring. The aim of this paper is to provide the importance and usefulness of having a fourth type of monitoring, so-called Integrated Monitoring, that links process, outcome and targets together. The paper also provides a conceptual overview, and illustrations that are used in the construction of the integrated monitoring system.
\end{abstract}

Keywords: traffic safety, monitoring system, performance indicators.

\section{Introduction}

Many cities recognise the need to monitor their own achievements and progress in road safety over time and in comparison to others. This monitoring will help a city to identify its existing road safety problems and determine key areas for actions to be taken in future.

Road safety priorities differ from one city to another in accordance to their size, population density, nature of traffic, accident characteristics, causes and challenges. For instance, casualties in respect of pedestrians, motorcycles and 
small mini-buses are more frequent in cities in developing countries e.g. in Asia and the Middle East than car casualties in cities in Western countries. Therefore cities take different approaches to solve their own traffic and accidents problems.

There are many problems that can cause the lack of road safety in a city. Part of these problems can be observed and monitored relatively simply such as poor road standards and maintenance, poor space and infrastructure, poor vehicles, road user behavior is unsafe, police enforcement is unsatisfactory, etc. At the same time, another part of the problems need in depth observation and monitoring such as the lack of professional "know how", little data available, inadequate urbanization, inadequate coordination between relevant stakeholders, little funding for road safety countermeasures, little awareness of the problem by public and policy makers, road safety education at schools and public is not satisfactory, decision processes are not efficient, no clear visions, etc [1-3].

Therefore, it has always been of interest to researchers/practitioners to develop a monitoring system in a city to monitor road safety development over time.

The Road Safety Programme (RSP) at any level (national, regional and local) in a country has proved to be as the best integrated approach to tackle road safety problems and monitor the development in many countries worldwide $[4,5]$. This programme is able to:

- Diagnose the road accident problem.

- Set up realistic and quantitative goals and priorities.

- Coordinate the work between all stakeholders involved.

- Allocate funds and resources for road safety actions.

- Design and implement cost-effectiveness measures towards targets.

- Monitor and evaluate improvements.

The evaluation and monitoring are important parts of applying any successful RSP. In order to identify priorities of measures in road safety in a city, it is important that there is first a clear understanding of the road accident causes at local level and the possible effectiveness of road safety improvements. This needs a good and comprehensive monitoring system in a city.

\section{Monitoring system in road safety}

The purposes of having a monitoring system in a city, in more specific, are:

- To see if the goals have been implemented and achieved according to the RSP and its targets. If not, the reasons must be found and actions need to be adjusted.

- To improve the efficiency and effectiveness of RSP.

- To increases the awareness road safety among public and policy makers.

- To ensure that the activities implemented are cost effective.

However, monitoring the road safety situation at city level requires comprehensive, reliable and updated data and information of road accidents. 
Further, the success of any specific strategy must be monitored properly, efficiently and regularly against the following criteria:

- The trends in fatalities and injuries in comparison with the target.

- The effectiveness of practices taken in response to each practice objective (e.g. reduction of drivers who violate speed limits by $30 \%$ ).

- Comparing similar situations in other similar cities in terms of e.g. size, socio-economic nature, traffic characteristics, etc and looking where best practices have been already used.

- Comparing the situation before and after implementing an action.

- The relevance of implemented activities to the priorities that were set up in the RSP.

- How well the coordination channels between different bodies involved in road safety in the city.

The monitoring process follows generally 5 main steps (see Figure 1), which are:

1. Set up aims and objectives on what should be monitored.

2. Select performance indicators in respect to the chosen objectives.

3. Collection of information and data.

4. Analyses and interpretation of data.

5. Review the results and implement recommendations.

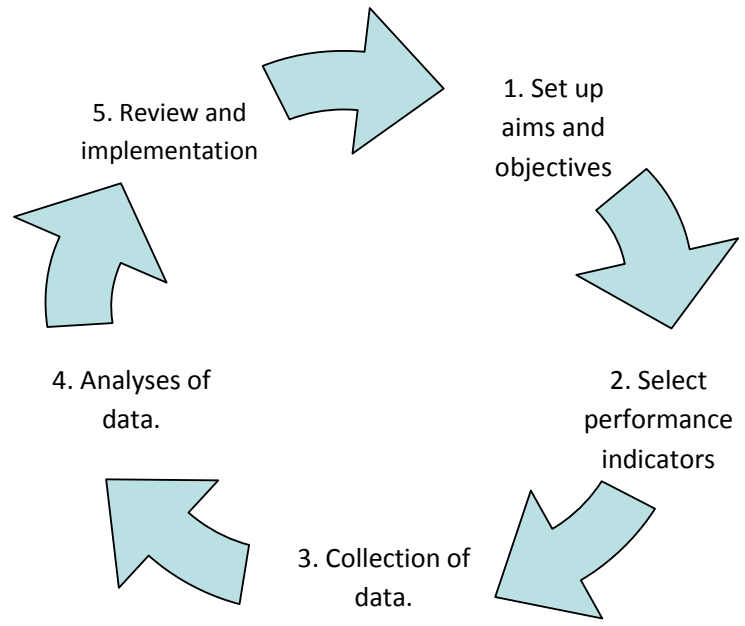

Figure 1: The monitoring process in road safety.

\section{Performance indicators}

The most important step of good monitoring is to come up with a comprehensive set of performance indicators, which includes as far as possible the main 
parameters in road safety instead of considering a few of them such as accident rates. The overall indicators should be chosen to reflect as much as possible the general aspects contributing to the road safety domain in the city of health, education, data collection, enforcement, legislation, engineering, etc.

\subsection{Criteria for selecting key performance indicators and dimensions in road safety}

On the way to develop a complete set of performance indicators that can be used for monitoring at city level and for comparison with other cities, one needs to remember that such a choice is restricted by certain conditions and requirements for both the indicators and data as following [6, 7]:

First, the indicators should have effect on road safety if any change in indicator occurred. They should represent the improvement in the situation and be reasonably accepted from different studies and literature surveys. Consider, for instance, the indicators that can be used to measure the change of the number of drivers above the legal BAC limits or driving exceeding speeds limits checked by police in one particular city over a year. This change could indicate a higher real traffic violation rate, but at the same time it can be a sign of an increased level of reporting and checking by police.

Second, one should care about the quality of each indicator and data. There are usually several data sources available from which we can find data to measure. But the data should come from one or more reliable source.

Third, the indicators chosen should be clear and with a precise definition. For example, an indicator of 'safer vehicles or urban roads standards' without a clear and precise definition of what we mean by the words 'safe' or 'standards' could easily lead to unclear collection of data. This might very well lead to a misunderstanding of what results are being achieved. In addition, for instance the number of deaths in accidents cannot be directly compared internationally since the individual definitions of road accident deaths differ from city to city. Most acceptable definition is the use the standard of dead within 30 days of the accident occurred, where many developing countries use the definition of deaths as on the spot or within 24 hours.

Fourth, the reliability of any indicator means that there is no real, major and sudden change in the indicator for a city being measured between different sources and over time.

Fifth, indicators should be simplified, to various degrees, in order to make it possible to measure and to be easily understood by policy makers and public. Some indicators are simple, have a relatively direct meaning and can be expressed in units which most people are comfortable with (e.g. motorcycles as a percentage of total fleet vehicles). Other indicators are more complicated but have a long experience in the field and are supported by research (e.g. deaths per vehicle kilometres travelled).

Sixth, we should always use a group of indicators relating to the desired objective we want to describe. But at the same time, we should not allow the set of indicators to become too many because that will take too much time to interpret and analyse (also it is a matter of cost). There is no exact number of 
indicators; rather the number should at least capture the results sufficiently for what we want to obtain. The chosen indicators should be as minimal as possible. For instance, road user behaviour in the city may require many indicators to capture the major aspects. However, we should remember that if we have identified a large number of indicators for a single aspect, this might mean that the aspect is too complex or too important or more data is being collected than necessary. In brief, it needs as well a balanced set of indicators as possible.

Seventh, as is known, the data collection process should be available year-toyear. This will make the indicators available and accessible whenever data is needed. The data and indicators should be updated more frequently.

Eighth, not everything in road safety that is known and is important can be counted. Several indicators of development involve subjective judgments. For example, the institutional organization and coordination in a city cannot be easily quantified into numbers. Often these judgments can be measured, using questionnaires or opinions of expert panels.

Ninth, computer databases can facilitate the accessibility to a large road safety data, indicators and other information from different cities. This will allow a quick analysis of the data with regular updating. Then the databases could provide this information to the city policy makers and to the public, which will help them in drawing attention to these phenomena. However, such database must be regularly maintained to ensure the accuracy of information.

\subsection{Key performance indicators in road safety}

According to Al-Haji [6], the safety situation can be quantified by a combination of factors in traffic (e.g. speed risk, alcohol and driving risk, etc.). For instance this can be indicated by the following formula [8]:

$$
\text { SAFETY }=\sum\left(w_{1} \cdot R_{1}+w_{2} \cdot R_{2}+\ldots . .+w_{n} \cdot R_{n}\right) \times \text { kilometres }
$$

where

$\mathrm{R}$ is the risk of particular factor

Kilometres is the exposure in traffic, and

$\mathrm{w}$ is the weight of the risk factor in a particular city

Additionally, $[9,10]$ accidents are caused by a combination of five main dimensions (human-vehicle-environment-road-system). These dimensions are not fully independent of each other and each dimension is influenced by many factors. This function can be expressed as:

$$
\mathrm{Y}=\mathrm{F}(\mathrm{X})
$$

where $\quad \mathrm{Y}$ is the number of accidents or the accident rate

$\mathrm{X}$ is a vector matrix of the explanatory variables in each of (humanvehicle-environment-road-system).

Many European studies also recognise the importance of having a comprehensive set of performance themes in road safety. The ETSC study [11] 
has identified four themes which are: first in behaviour: speed, alcohol, seat belts; second vehicles: passive safety; third roads: percentage of roads meeting design standards; and fourth on trauma management: arrival time and quality of medical treatment.

SafetyNet [12] has focused on seven performance areas which are: the use of alcohol and drugs, speeds, use of seatbelts and crash helmets, use of daytime running lights, vehicles, roads, and trauma management.

A research work by Ecorys and SWOV [13] presented possible operational and output indicators in road safety. In such an effort, the study identified some several key areas such as: increased enforcement, drivers' licenses, passive and active safety, infrastructure, commercial drivers, and trauma management.

Rumar [14] described the road safety problem as a function of three dimensions, which are 'exposure', 'accident risk' (for a certain exposure) and 'injury risk'. This was illustrated as the volume of the cube in which determines the size of the road safety problem. Any change in any one of these three dimensions will change the whole safety situation in a city.

Following the previous model, the performance factors can be grouped into three categories of exposure, risk and consequences as shown in the following table [6].

Table 1: $\quad$ Performance factors influencing exposure, risk and consequences.

\begin{tabular}{|c|}
\hline Factors influencing exposure to traffic \\
\hline - Economic factors per capita \\
\hline - Urban population density, and other demographic factors \\
- Type of travel mode choice \\
\hline Factors influencing risk of accident \\
\hline - To driver: speed, alcohol and driving, being young, etc. \\
\hline - To groups of road users: unprotected road users \\
\hline - To vehicles: motorcyclists, heavy trucks, non-motorised traffic, vehicle \\
inspection, age of car, etc. \\
\hline - To roads: unpaved, defects in road design, poor maintenance, etc. \\
\hline - To environment: darkness, fog, ice, etc. \\
\hline Factors influencing accident severity \\
\hline - Human factors: speed, helmets worn by users of motorcyclists and cyclists \\
\hline - Vehicle: passive safety (e.g. seatbelts, airbags, child safety seat, vehicle \\
safety and protection standards) \\
\hline - Crash-protective roadsides, guardrails, barriers \\
\hline - Poor rescue and pre-hospital emergency care \\
\hline - Poor city health care system \\
\hline
\end{tabular}

As one can see, from the summary table that the three categories exposurerisk-consequences are highly interrelated and many indicators can be included in more than one category (e.g. speed can influence both risk and consequences). 
Based on the brief review and discussion presented above, nine dimensions (groups of performance indicators) can be identified of which each corresponds to a special area of road safety. The dimensions listed are:

1. Traffic risk: the risk of a person being killed in road accidents per vehicle or per vehicle-km.

2. Personal risk: the risk of a person being killed in road accident per number of inhabitants.

3. Changing trend of accident rates: the percentage change of death trend over time. There is an indication of an improvement in the overall traffic risk and personal risk in most cities in developing countries, while the number of deaths has been reduced mostly in developed countries alone over time.

4. Safer vehicles: this dimension assesses the safety characteristics of vehicles in a city that affect the number of vehicle-related crashes (e.g. type of vehicle, new cars in a city, inspection of vehicles, index of national crashworthiness, vehicle inspection, etc.).

5. Safer roads: this dimension measures different aspects of the quality and conditions of roads in a city in relation to road safety (e.g. motorway level, paved roads and national expenditure on roads).

6. Safer people (road user behaviour): this dimension assesses human behaviour and traffic safety with respect to speeding, drink-driving, helmet use, seatbelt use, driver training, etc.

7. The socioeconomic factors: this category considers a city's development and investments in relation to health and rescue level, education level per capita, urban population, income level, etc.

8. Traffic police and enforcement: measures traffic police and enforcement effectiveness levels in the city.

9. Road safety organisational structure: measures the efficiency of the overall road safety programme, action plans, data system, research, legislations and how much cooperation is made between the key bodies responsible for road safety actions in the city.

It can be seen that the nine dimensions measure road safety development in terms of direct or indirect classes. This can be explained that direct indicators are derived measures (outcomes), for example death rates (traffic risk and personal risk) are considered as direct measures for explaining national or international road safety development. The indirect dimensions are individual means (process and practices) in the way they could describe the development in a particular theme to road safety. The indirect dimensions can be also seen from top-down or bottom-up approach according to their contributions to the national road safety development. For instance, policymakers can focus on human-vehicle-road dimensions to make changes, or they can focus on organisational structure (e.g. education, legislations, and traffic safety management), socio-economic 
system and enforcement to make changes. However, both of these approaches contribute toward the same goal of road safety development.

\section{Integrated monitoring system in road safety}

In road safety, monitoring system can be categorised under three types, which are:

1. Monitoring the process and practices: monitoring the process of implementation by tracking the inputs in terms of the responsible persons, funds allocated and used, equipment needed to achieve actions, changes in policies, management instruments, etc. For example, by monitoring the process and practices of launching a number of road safety campaigns in a city to increase seat belt usage rate.

2. Monitoring the outcomes and impacts: monitoring the overall outcomes of the actions implemented, which monitor the direct results of actions in terms of road accident death rates reduction e.g. as a result of traffic safety campaigns in a city. Additionally, this type of monitoring monitor the sub-outcomes of key practices that are related e.g. to human-vehicle-road performance (e.g. an increase rate of seat belt use in front seats by $20 \%$ in a city due to effective traffic safety campaigns). It is also important to consider that impact monitoring that looks into account possible consequences involved in any action.

3. Monitoring the targets and strategies: it is used to monitor the direction of progress ahead in comparison to the targets stated in the city action plan. This will help city in knowing the gab of performance. For example, by monitoring the achieved target in seat belt usage due to effective campaigning in a city in comparison to the preferred target.

However, there is an emphasis of the need for an integration between the above three types of monitoring in what so called "The Integrated Monitoring System". The aim of integrated monitoring system is to assess the overall results of monitoring undertaken in terms of process, outcomes and targets simultaneously, see Figure 2.

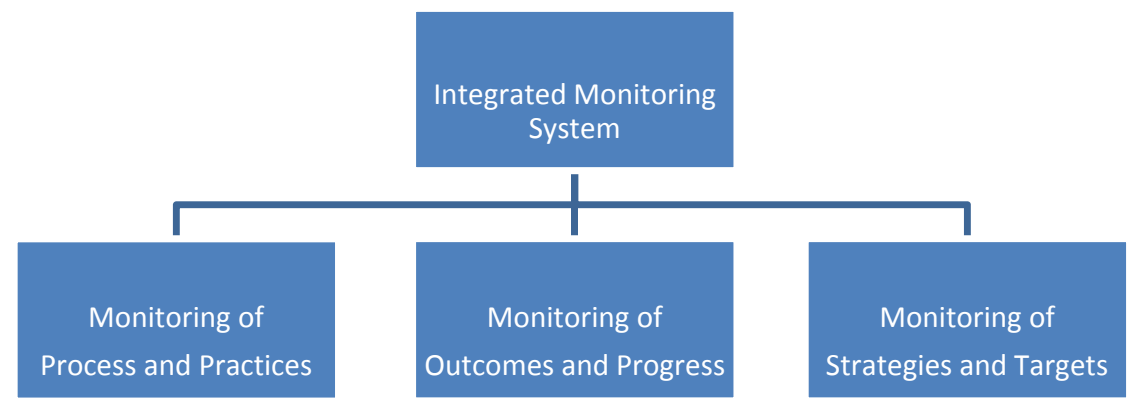

Figure 2: $\quad$ The framework of integrated monitoring system in road safety. 
It is also important to emphasise that the overall outcome of safety in terms of accident death rates may answer partly if city performs better over time period, but it will not answer why and what actions this city have taken to improve its performance. Accident death rates focus only on the superficial level (product) and not on the overall system (process, practices, targets and strategies).

Additionally, there is no guarantee that cities with good scores only in the quality of the product (accident death rates) will not have trouble in the future in terms of number of deaths and injuries. Maybe there is a low level of death rates (traffic risk and personal risk) for some particular reasons but there is probably, at the same time, an increasing risk somewhere else (e.g. enforcement, speed, alcohol and driving, pedestrians, etc.). Accident death rates reflect only the exposure measures in terms of number of population and number of vehicles, but they do not reflect the overall continuous improvement in road safety.

\section{Conclusions}

The progress in road safety in any city will be minimal unless the city has a good system to rely on monitoring and problem formulation. The study has shown that the integrated monitoring is more than necessary for describing and monitoring the development of road safety in cities. If there is a failure in any area of process-outcomes-targets, the development in a city will fail as well. Thus any successful action plan in road safety has to link process, practices to the targets results. If the plan shows poor performance in any areas, changes can be made before a worsening situation will actually start. Therefore, integrated monitoring system may provide an early and direct warning signal to policy makers, practitioners and public.

\section{References}

[1] Al-Haji, G., Asp, K., Shbeeb, L., and Awad, W. (2008). Sweden-Jordan Research Link on Children and School Pedestrians' Safety in Urban Areas. Proc of The First International Engineering Sciences Conference (IESC08), 2-4 November, 2008, Aleppo, Syria.

[2] Al-Haji, G., Asp, K., (2007). Traffic accidents reduction strategy, best practices from European States. Proc of The International Conference in Traffic \& Its Contemporary Issues, May 12-14, 2007, Kuwait.

[3] Al-Haji, G., Asp, K., (2002). Road Safety Perspective in Arab CountriesComparative Study and Analysis of Progress, Proc of SORIC' 02 Conference (Safety on Roads), Bahrain.

[4] Al-Haji, G., Asp, K., Ericsson M., (2008). Academic Curriculum and Research Development in Road Safety. Proc of the 4th International Gulf Conference on Roads, 10-13 November, 2008, Doha, Qatar.

[5] Al-Haji, G., Asp, K., (2006). New Tools for Assessing and Monitoring National Road Safety Development. Proc of the 2nd International Road Safety Conference, Dubai - United Arab Emirates. 
[6] Al-Haji, G. (2007). Road Safety Development Index (RSDI), Theory, Philosophy and Practice, Dissertation No. 1100, Linköping University, Sweden.

[7] Al-Haji, G., Asp, K., (2006). The Evolution of International Road Safety Benchmarking Models: Towards a Road Safety Development Index (RSDI). The International Journal Science \& Technology for Highways, Vol.3, pp.3-9.

[8] Koornstra M.J., (1996). The quantifying of road safety developments, Proceedings of the Conference Road Safety in Europe, VTI conference, Sweden, pp167-186.

[9] Navin, F., Bergan, A., Qi , J., (1994). A Fundamental Relationship for Roadway Safety: A Model for Global Comparisons. Transportation Research Board, Transportation Research Record, 1441, Washington D.C., pp. 53-60.

[10] Haight, F., (1983). Traffic Safety in Developing Countries, Journal of Safety Research, Vol. 14, No. 1, pp. 1-12.

[11] ETSC, (2003). Transport Safety Performance in the EU. A Statistical Overview, Brussels.

[12] SafetyNet, (2005). Annual Statistical Report 2004, Building the European Road Safety Observatory Workpackages. European Commission.

[13] Ecorys and SWOV, (2005). Impact Assessment Road Safety Action Programme- Assessment for mid term review. The European Commission.

[14] Rumar K. (1999). Transport safety visions, targets and strategies: beyond 2000. First European Transport Safety lecture, Brussels, European Transport Safety Council. 